\title{
Using a Multivariate Approach to Compare Lipid Extraction Protocols from Microalgae Scenedesmus sp.
}

\author{
Daiane F. Dall'Oglio, ${ }^{a, b}$ Laísse C. de Sousa, ${ }^{a}$ Samuel A. A. de Sousa, ${ }^{a}$ \\ Marco A. S. Garcia, ${ }^{a}$ Edymilaís S. Sousa, ${ }^{a}$ Sidney G. de Lima, ${ }^{a}$ Pelrry S. Costa, ${ }^{a}$ \\ Abhishek Guldhe, ${ }^{c}$ Faizal Bux, ${ }^{c}$ Edmilson M. de Moura ${ }^{a}$ and \\ Carla V. R. de Moura ${ }^{\circledR} * a$ \\ ${ }^{a}$ Departamento de Química, Universidade Federal do Piauí, 64049-550 Teresina-PI, Brazil \\ ${ }^{b}$ Centro de Ciências Agrárias e Ambientais, Universidade Federal do Maranhão, \\ 65500-000 Chapadinha-MA, Brazil \\ 'Institute for Water and Wastewater Technology, Durban University of Technology, \\ P.O. Box 1334, 4000 Durban, South Africa
}

\begin{abstract}
Microalgae lipid-derived biofuels is considered promising candidates for substitution of petroleum-based energy sources. However, the lipid extraction from the algal biomass stands as a challenge due to its low yields and cost-intensive cell disruption procedures. In this study a multivariate optimization of the extraction conditions was suggested, aiming a maximization of the lipid extraction from Scenedesmus sp. microalgae grown using wastewater as a nutrient medium. The extraction method, extraction time, solvent mixture and pretreatment were considered between upper and lower levels in order to access their significance, including their interactions, on the experimental response, while using a reduced number of experiments. The studies were performed using low-cost extraction methods (magnetic stirring and ultrasonication). The optimal extraction condition was obtained using $\mathrm{CHCl}_{3}: \mathrm{MeOH}(2: 1)$ solvent mixture, in a 2-hour extraction period using ultrasonication. Fatty acid profiles of extracted lipids were also evaluated.
\end{abstract}

Keywords: microalgae, lipid extraction, multivariate approach

\section{Introduction}

At present, a considerable part of the world's energy is derived from unrenewable fossil fuel sources, ${ }^{1-3}$ despite their rate of depletion and the effects of the generated greenhouse gases on global climate change. ${ }^{4-6}$ Considering such conditions, the search for renewable and sustainable fuels has been intensifying, stimulating large-scale biodiesel synthesis. ${ }^{7-9}$ However, regarding the substrates traditionally used for biofuel, commercial production of fatty acid methyl ester (FAME) from edible oils is no longer sustainable since it displaces food production, ${ }^{10}$ and the production of nonedible oils is coupled with the availability of arable lands for its cultivation. ${ }^{11}$ Thus, the exploration of alternative fuels has focused on the so-called third-generation biofuels, ${ }^{12}$ i.e., the production of low-cost and renewable biomass with high potential to produce energy. From an environmental

*e-mail: carla@ufpi.edu.br perspective, microalgae present several advantages over the oilseed largely used for oil extraction ${ }^{13}$ as they do not need cultivable fields, can be grown using wastewater, present higher growth rates than terrestrial plants and have a greater energy density than vegetable feedstocks. ${ }^{14}$

The lipid extraction from microalgae biomass consists of disrupting the algae cell walls ${ }^{15}$ using mechanical or chemical approaches (organic solvent-based and solventfree methods).$^{16}$ Thus, the amount of lipids obtaining is of critical importance and systematic studies focused on this matter are somehow scarce using multivariate approaches. Such approaches open up the possibility to evaluate the individual effects of variables and their interactions. Among many advantages, the multivariate analysis allows a knowledge of the best experimental conditions, while using a reduced number of experiments. ${ }^{17}$

Scenedesmus sp. is an excellent biodiesel feedstock due to its robustness towards open cultivation. ${ }^{18}$ Moreover, this species can accumulate lipid under nutrient-deficient 
mediums with a suitable fatty acid profile, i.e., it can be cultivated in wastewater without compromising on quality. ${ }^{19}$ Several procedures were proposed for lipid extraction, such as supercritical fluid extraction, ${ }^{20}$ microwave-assisted extractions, ${ }^{21-23}$ pressurized liquid extraction, ${ }^{23,24}$ osmotic shock, ${ }^{25}$ and ultrasound-assisted extraction. ${ }^{26,27}$ However, considering that ultrasonication requires a single unit, has a low power input, ${ }^{28}$ and is advantageous due to the fast operational time and low set-up cost,${ }^{15}$ which is more commercially suitable, its exploration as lipid extractor has an appealing significance. Abomohra et al. ${ }^{21}$ studied an optimized procedure for lipid extraction from Scenedesmus obliquиs; however, using a univariate analysis. The univariate analysis does not deal with relationships among the parameters since the main purpose is a simplified description. For that matter, a specific parameter is varied, such as solvent mixtures, maintaining all the other variables under a specific condition. The process is repeated for all the parameters considering the best condition previously obtained. The multivariate approach is able to describe the relationship among the parameters in a comprehensive methodology.

To the best of our knowledge, there is a lack of literature dealing with Scenedesmus sp. microalgae using a multivariate approach. In addition, even considering it is impossible to predict whether or not biodiesel from microalgae will give rise to future incomes, it is undeniable that this feedstock has a potential application. ${ }^{29}$ Hence, the studies herein presented aimed at investigating the optimum conditions for oil extraction from Scenedesmus sp. For the proposed study, a solvent based lipid extraction method was investigated for the biodiesel-promising microalgae substrate. The best conditions were searched among different solvent mixtures, extraction times, pretreatments and cell-disruption methods under sonication bath conditions and magnetic stirring. Analysis of variance (ANOVA) was used to verify the significance of effects. In addition, we evaluated the back-extraction of the biomass residue and performed gas chromatography-mass spectrometry (GC-MS) for determination of the lipid profile obtained from the different extraction procedures.

\section{Experimental}

\section{Materials and methods}

All the experimental procedures were performed using Scenedesmus sp. microalgae, which was isolated from Kwa-Zulu Natal province, in the Durban region, South Africa. The cultivation was performed using post-chlorinated effluent wastewater with supplementation of BlueGreen nutrients, BG11 $1^{30}$ (consisting of $1.5 \mathrm{~g} \mathrm{~L}^{-1}$ $\mathrm{NaNO}_{3}, 0.075 \mathrm{~g} \mathrm{~L}^{-1} \mathrm{MgSO}_{4} \cdot 7 \mathrm{H}_{2} \mathrm{O}, 0.036 \mathrm{~g} \mathrm{~L}^{-1} \mathrm{CaCl}_{2} \cdot 2 \mathrm{H}_{2} \mathrm{O}$, $0.006 \mathrm{~g} \mathrm{~L}^{-1}$ citric acid, $0.01 \mathrm{~g} \mathrm{~L}^{-1} \mathrm{Na}-\mathrm{EDTA}, 2.86 \mathrm{~g} \mathrm{~L}^{-1}$ $\mathrm{H}_{3} \mathrm{BO}_{3}, 0.036 \mathrm{~g} \mathrm{~L}^{-1} \mathrm{CaCl}_{2} \cdot 4 \mathrm{H}_{2} \mathrm{O}, 0.06 \mathrm{~g} \mathrm{~L}^{-1} \mathrm{Fe}$ ammonium citrate, $0.02 \mathrm{~g} \mathrm{~L}^{-1} \mathrm{Na}_{2} \mathrm{CO}_{3}, 0.04 \mathrm{~g} \mathrm{~L}^{-1} \mathrm{~K}_{2} \mathrm{HPO}_{4} \cdot 3 \mathrm{H}_{2} \mathrm{O}$, $2.86 \mathrm{~g} \mathrm{~L}^{-1} \mathrm{H}_{3} \mathrm{BO}_{3}, 1.81 \mathrm{~g} \mathrm{~L}^{-1} \mathrm{MnCl}_{2} .4 \mathrm{H}_{2} \mathrm{O}, 0.222 \mathrm{~g} \mathrm{~L}^{-1}$ $\mathrm{ZnSO}_{4} \cdot 7 \mathrm{H}_{2} \mathrm{O}, 0.390 \mathrm{~g} \mathrm{~L}^{-1} \mathrm{Na}_{2} \mathrm{MoO}_{4} \cdot 2 \mathrm{H}_{2} \mathrm{O}, 0.079 \mathrm{~g} \mathrm{~L}^{-1}$ $\left.\mathrm{CuSO}_{4} \cdot 5 \mathrm{H}_{2} \mathrm{O}, 0.049 \mathrm{~g} \mathrm{~L}^{-1} \mathrm{Co}\left(\mathrm{NO}_{3}\right)_{2} \cdot 6 \mathrm{H}_{2} \mathrm{O}\right)$ at Kingsburg wastewater treatment (Durban, South Africa) plant in $3000 \mathrm{~L}$ open circular ponds. The biomass was harvested after 3 weeks of cultivation using a disc stack centrifuge. Harvested biomass is oven dried and then pulverized using a blender for further use in extraction experiments.

\section{Experimental design parameters}

The lipid extraction protocols were performed according to the literature, with modifications. ${ }^{31}$ In a typical procedure, $2 \mathrm{~g}$ of dried microalgal biomass were suspended in $30 \mathrm{~mL}$ of a chosen solvent mixture and maintained in ultrasonication or magnetic stirring under specific conditions described hereafter. Then, the biomass residue was separated from the organic phase by filtration and the solvent was evaporated under reduced pressure. All the extractions were performed in triplicate.

A full $2^{4}$ factorial design was used to assess the significance of the effects and the interactions of the variables on the lipid extraction. The algal biomass obtained from the drying process was subjected to different disruption techniques. The evaluated variables for the experiment design I were: solvent mixture, extraction method, extraction time and pretreatment (Table 1). The extraction methods were ultrasonication at $60{ }^{\circ} \mathrm{C}$ (Unique USC-1850A, $154 \mathrm{~W}, 25 \mathrm{kHz}$ ) and magnetic stirring (600 rpm, Arec X, Velp, Scientifica, at 60 and $150{ }^{\circ} \mathrm{C}$ ). The 16 assays were performed randomly within 5 days to avoid systematic errors. The response was analyzed as the amount of obtained lipids in relation to the mass of microalgae used, expressed as a percentage.

Table 1. Full $2^{4}$ factorial design for the solvent mixture, extraction technique, extraction time and pretreatment. (experiment design I)

\begin{tabular}{lccc}
\hline \multirow{2}{*}{ Variable } & \multirow{2}{c}{ Symbol } & \multicolumn{2}{c}{ Factor level } \\
\cline { 3 - 4 } & & $\mathrm{CHCl}_{3}: \mathrm{EtOH}$ & $\mathrm{CHCl}_{3}: \mathrm{MeOH}$ \\
Solvent mixture & $\mathrm{X}_{1}$ & $(2: 1)$ & $(2: 1)$ \\
& & ultrasonication & magnetic stirring \\
Extraction method & $\mathrm{X}_{2}$ & at $60^{\circ} \mathrm{C}$ & at $60^{\circ} \mathrm{C}$ \\
Extraction time $/ \mathrm{h}$ & $\mathrm{X}_{3}$ & 1 & 2 \\
Pretreatment & $\mathrm{X}_{4}$ & water bath & oven \\
\hline
\end{tabular}


Based on findings from the experiment design I, another full $2^{4}$ factorial design (experiment design II), that would evaluate any other possible interaction, was proposed. The evaluated variables for the experiment design II are presented in Table 2.

Table 2. Full $2^{4}$ factorial design for the solvent mixture, magnetic stirring, extraction time and pretreatment (experiment design II)

\begin{tabular}{lccc}
\hline \multirow{2}{*}{ Variable } & \multirow{2}{*}{ Symbol } & \multicolumn{2}{c}{ Factor level } \\
\cline { 3 - 4 } & & -1 & +1 \\
\hline \multirow{2}{*}{ Solvent mixture } & $\mathrm{X}_{1}$ & $\begin{array}{c}\mathrm{CHCl}_{3}: \mathrm{EtOH} \\
(2: 1)\end{array}$ & $\begin{array}{c}\mathrm{CHCl}_{3}: \mathrm{MeOH} \\
(2: 1)\end{array}$ \\
$\begin{array}{l}\text { Magnetic stirring } \\
\text { temperature } /{ }^{\circ} \mathrm{C}\end{array}$ & $\mathrm{X}_{2}$ & 60 & 150 \\
Extraction time $/ \mathrm{h}$ & $\mathrm{X}_{3}$ & 1 & 2 \\
Pretreatment & $\mathrm{X}_{4}$ & water bath & oven \\
\hline
\end{tabular}

For the experiment design II, 16 experiments were performed. As the last investigation, the time of extraction was considered, based on the experiment design I. In this context, the differences among the response for 2,4 and $6 \mathrm{~h}$ of extraction time (in triplicate), using ultrasonication at $60^{\circ} \mathrm{C}$ as extraction method, $\mathrm{CHCl}_{3}: \mathrm{MeOH}(2: 1)$ as solvent and water bath as pretreatment, were accessed by means of the one-way ANOVA.

\section{Lipid back-extraction}

To evaluate the obtaining of more oil from the microalgae, a new extraction (back-extraction) procedure was performed from the algal-residue biomass. The residue was dried in an oven at $60{ }^{\circ} \mathrm{C}$ overnight before its usage; then subjected to lipid extraction using the same procedure as described before.

\section{Fatty acid profile characterization}

The analysis of the fatty acid profile was performed by gas chromatography. An esterification reaction was conducted for each sample before the injection. The reactions were performed according to Hartman and Lago, ${ }^{32}$ with modifications. In a typical procedure, $5 \mathrm{~mL}$ of a methanolic solution of $\mathrm{NaOH}\left(0.5 \mathrm{~mol} \mathrm{~L}^{-1}\right)$ were added to a $50-\mathrm{mL}$ volumetric flask containing $500 \mathrm{mg}$ of the oil to be reacted. The mixture was boiled in a reflux system for $5 \mathrm{~min}$ before the addition of $15 \mathrm{~mL}$ of the esterification reagent (a mixture of $2 \mathrm{~g}$ of ammonium chloride, $60 \mathrm{~mL}$ of methanol and $3 \mathrm{~mL}$ of sulfuric acid, which were refluxed for $15 \mathrm{~min}$ ). The esterification reaction was conducted in a reflux system for $10 \mathrm{~min}$ and transferred for a separating funnel and washed twice with a mixture of $50 \mathrm{~mL}$ of distilled water and $25 \mathrm{~mL}$ of hexane. The aqueous phase was discarded and from the organic one, $1 \mu \mathrm{L}$ was injected in the GC.

The GC-MS analyses were performed using a GCMS-QP2010 SE Shimadzu instrument. Chromatographic separation was achieved by using fused silica capillary column, $\mathrm{SLB}^{\mathrm{TM}}-5 \mathrm{~ms}(30 \mathrm{~m} \times 0.25 \mathrm{~mm} \times 0.25 \mu \mathrm{m})$. The temperature program for the oven was the following: an initial temperature of $100^{\circ} \mathrm{C}(0.5 \mathrm{~min}$ hold $)$, followed by a ramp of $4{ }^{\circ} \mathrm{C} \min ^{-1}$ up to a final temperature of $240{ }^{\circ} \mathrm{C}$ (10 min hold). The split/splitless (S/SL) injector was used in split mode at the ratio of $1: 1$ and was set at $220^{\circ} \mathrm{C}$. The carrier gas was helium (99.9999\%) at a constant flow rate of $1.0 \mathrm{~mL} \mathrm{~min}{ }^{-1}$. The transfer line temperature was $240{ }^{\circ} \mathrm{C}$. The quadrupole mass spectrometer was operated in full scan mode over the mass range 47-500 Da. The ion source was operated in electron impact (EI) mode at $70 \mathrm{eV}$. The identification of components was performed by comparison of elution order, retention times, mass spectra with literature data and with a mixture of methyl esters (FAME Mix, CRM47885, lot XA16739V). The analyses were also carried out by gas chromatography with flame ionization detection (GC-FID) in a Shimadzu GC-2010 Plus instrument, using a capillary column coated with NST $05 \mathrm{HT}(30 \mathrm{~m} \times 0.25 \mathrm{~mm} \times 0.25 \mu \mathrm{m})$. The method used was similar to that described above for GC-MS. The carrier gas was $\mathrm{N}_{2}\left(30 \mathrm{~mL} \mathrm{~min}^{-1}\right)$; the flow for $\mathrm{H}_{2}$ and $\mathrm{O}_{2}$ was 40 and $400 \mathrm{~mL} \mathrm{~min}^{-1}$, respectively. The GC-FID chromatogram was used to determine the relative concentrations using peak areas.

\section{Results and Discussion}

Some of us have published the production of biodiesel from the Scenedesmus sp. microalgae. Since the acid value of the lipids extracted from the algal biomass is high, with a high value of free fatty acids $\left(>4 \mathrm{mg} \mathrm{KOH} \mathrm{g}^{-1}\right)$, alkali catalysts are disregarded due to the possibility of saponification. ${ }^{33}$ Using $\mathrm{H}_{2} \mathrm{SO}_{4}, 91.75 \%$ of yield for biodiesel was obtained, ${ }^{34}$ while the tungstated zirconia solid acid catalyst yielded $71 \%$ using sonication. ${ }^{22}$ Thus, aiming at the feasibility and strengthening of biodiesel production as an alternative for fossil fuel sources, the lipid extraction is a critical step. Bearing that in mind, we have put a lot of effort into such a process using a multivariate method, which is highly applied in the literature ${ }^{35-37}$ since different matrices present different responses.

\section{Experimental design}

A multivariate approach was proposed to study the effects of the extraction conditions on total lipid content obtained 
from the microalgae Scenedesmus sp. This methodology regards the individual effects of the variables and their interactions. The variables studied were: solvent mixtures, $\mathrm{CHCl}_{3}: \mathrm{EtOH}(2: 1)$ and $\mathrm{CHCl}_{3}: \mathrm{MeOH}(2: 1)$; ultrasoundassisted extraction (at $60{ }^{\circ} \mathrm{C}$ ); magnetic stirring coupled with a condenser $\left(60\right.$ and $\left.150{ }^{\circ} \mathrm{C}\right)$; extraction time $(1,2$, 4 and $6 \mathrm{~h}$ ) and pretreatment (water bath and oven). The dependent variable corresponds to the amount of obtained lipid in relation to the mass of microalgae used, expressed as a percentage. It is worth mentioning that the use of chloroform and methanol for lipid extraction is well-known since 1957. The original procedure was applied to animal tissues ${ }^{38}$ however, matrix effects in biological samples have been recognized as complex interferences, which are needed to be studied before any quantification..$^{39}$ Thus, although many studies use the same procedure, it is important to study different samples rather than make a generalization.

The investigations of extraction conditions were carried out using a full $2^{4}$ factorial design, as presented in Table 1 (experiment design I). For the proposed strategy, the independent variables were qualitative and quantitative, i.e., extraction time is the quantitative parameter and the other ones, qualitative. Table 3 shows the results of the experimental assays (16 runs) for the lipid extraction, presenting the coded levels of the variables (according to Table 1). The experiments were performed in a random manner, within a period of 5 days.

Table 3. Experiment design I (full $2^{4}$ factorial design) and responses (total lipids yield) obtained for each experiment

\begin{tabular}{|c|c|c|c|c|c|}
\hline \multirow{2}{*}{ Experiment } & \multicolumn{4}{|c|}{ Variable $^{\mathrm{a}}$} & \multirow{2}{*}{$\begin{array}{l}\text { Total lipid } \\
\text { yield / \% }\end{array}$} \\
\hline & $\mathrm{X}_{1}$ & $\mathrm{X}_{2}$ & $\mathrm{X}_{3}$ & $\mathrm{X}_{4}$ & \\
\hline 1 & -1 & -1 & -1 & -1 & 6.39 \\
\hline 2 & -1 & -1 & -1 & +1 & 2.81 \\
\hline 3 & -1 & -1 & +1 & -1 & 5.26 \\
\hline 4 & -1 & -1 & +1 & +1 & 4.79 \\
\hline 5 & -1 & +1 & -1 & -1 & 4.17 \\
\hline 6 & -1 & +1 & -1 & +1 & 4.39 \\
\hline 7 & -1 & +1 & +1 & -1 & 5.13 \\
\hline 8 & -1 & +1 & +1 & +1 & 4.19 \\
\hline 9 & +1 & -1 & -1 & -1 & 7.50 \\
\hline 10 & +1 & -1 & -1 & +1 & 5.90 \\
\hline 11 & +1 & -1 & +1 & -1 & 6.23 \\
\hline 12 & +1 & -1 & +1 & +1 & 7.70 \\
\hline 13 & +1 & +1 & -1 & -1 & 6.29 \\
\hline 14 & +1 & +1 & -1 & +1 & 5.48 \\
\hline 15 & +1 & +1 & +1 & -1 & 6.06 \\
\hline 16 & +1 & +1 & +1 & +1 & 5.72 \\
\hline
\end{tabular}

${ }^{\mathrm{a} A c c o r d i n g}$ to descriptions of Table 1 .
The Pareto chart in Figure 1, resulting from the standardized effects estimate from the experimental design I for each interaction and factor, shows both the magnitude and importance of the parameters. The horizontal dashed line corresponds to the $t$ value from the Student's distribution with $95 \%$ of confidence $(p=0.05)$ and proper degrees of freedom. Thus, those individual effects or interactions that extends past the horizontal dashed line are significant. It can be seen that the only significant parameter for the extraction is the solvent mixture. The positive value suggests that the response maximization (increasing of total lipids yield) occur at the higher level, i.e., with the proportion of $\mathrm{CHCl}_{3}: \mathrm{MeOH}$ of $2: 1$. This data is in accordance with the literature; Cho et al. ${ }^{40}$ in a univariate approach, has obtained such parameter (solvent mixture of $\mathrm{CHCl}_{3}: \mathrm{MeOH}$ of 2:1) as the most significant for Scenedesmus obliquus lipids extraction as well. Abomohra et al. ${ }^{21}$ present similar findings. However, it is important to emphasize that in univariate analyses the response maximization is only found in certain special conditions corresponding to those whose interactions of the variables have little or no influence in the chosen experimental domain. Since the absence of interactions is a priori never known, a multivariate approach must always be done. The effects of the other variables, i.e., extraction method, time and pretreatment, and interactions were not significant since they are not statistically different from the experimental variation.

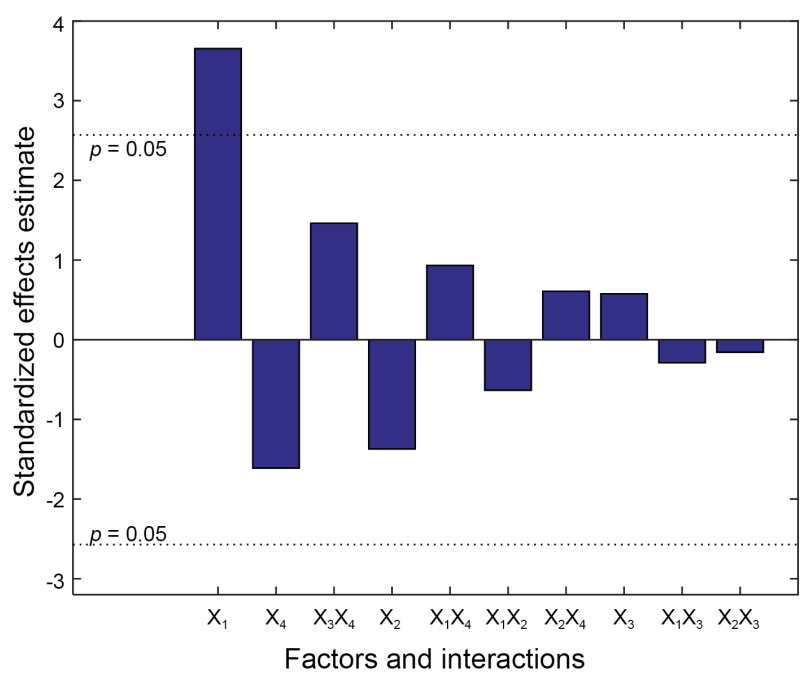

Figure 1. Pareto chart for the experiment design I with a horizontal dashed line corresponding to a significance level of $p=0.05$, which indicates the solvents mixture significance for the lipids extraction. The symbols are presented in Table $1 ; X_{i} X_{j}$ stands for the interaction between $i$ and $j$ factors.

It is important to note that despite the Pareto chart in Figure 1 (experiment design I) revealed a very important piece of information for the lipids extraction optimization, 
different levels of temperature were not considered. Previously, the analyses were all performed at $60^{\circ} \mathrm{C}$, both for ultrasonication- and magnetic stirring-assisted extractions. The ultrasonication-assisted extraction necessarily occurs in the liquid phase, i.e., the procedure has to be performed under the boiling point of the solvent, where the acoustic cavitation causes the formation of microbubbles. ${ }^{41-43}$ Alternatively, the magnetic stirring-assisted method can be applied under different temperatures. Therefore, a second experiment design (experiment design II) was proposed to investigate any significant statistical effect involving the temperature and/or its interactions with other variables on the extraction. The extraction experiments were carried out using a full $2^{4}$ factorial design, as shown in Table 2. Table 4 shows the results of the experimental assays (16 runs), presenting the coded levels of the variables (according to Table 2). The experiments were performed in a random manner, within a period of 5 days.

Table 4. Experiment design II (full $2^{4}$ factorial design) and responses (total lipids yield) obtained for each experiment

\begin{tabular}{lccccc}
\hline \multirow{2}{*}{ Experiment } & \multicolumn{4}{c}{ Variable $^{\mathrm{a}}$} & \multirow{2}{*}{$\begin{array}{c}\text { Total lipid } \\
\text { yield / \% }\end{array}$} \\
\cline { 2 - 4 } 1 & $\mathrm{X}_{1}$ & $\mathrm{X}_{2}$ & $\mathrm{X}_{3}$ & $\mathrm{X}_{4}$ & 4.17 \\
2 & -1 & -1 & -1 & -1 & 3.37 \\
3 & -1 & -1 & -1 & +1 & 4.47 \\
4 & -1 & -1 & +1 & -1 & 2.47 \\
5 & -1 & -1 & +1 & +1 & 5.13 \\
6 & -1 & +1 & -1 & -1 & 4.19 \\
7 & -1 & +1 & -1 & +1 & 5.02 \\
8 & -1 & +1 & +1 & -1 & 3.65 \\
9 & -1 & +1 & +1 & +1 & 6.29 \\
10 & +1 & -1 & -1 & -1 & 5.48 \\
11 & +1 & -1 & -1 & +1 & 5.38 \\
12 & +1 & -1 & +1 & -1 & 6.52 \\
13 & +1 & -1 & +1 & +1 & 6.06 \\
14 & +1 & +1 & -1 & -1 & 6.88 \\
15 & +1 & +1 & -1 & +1 & 5.19 \\
16 & +1 & +1 & +1 & -1 & 4.49 \\
\hline
\end{tabular}

${ }^{\text {a According to descriptions of Table } 2 .}$

The Pareto chart resulting from the experiment design II in Figure 2 shows again that the only factor significant is the solvent mixture. The other factors do not show significant interaction among them to produce the maximization of responses. Both experimental designs suggest the following: (i) the proportion of $\mathrm{CHCl}_{3}: \mathrm{MeOH}$ of 2:1 is the best to maximize the lipids extraction of Scenedesmus sp. microalgae; (ii) this solvent composition does not interact significantly with the extraction (ultrasonication or magnetic stirring) techniques nor with the extraction times; (iii) there is also no significant interaction with the temperature between the levels of 60 and $150{ }^{\circ} \mathrm{C}$, using magnetic stirring as extraction method; $(i v)$ the pretreatment procedures are not significant and do not interact with the other variables; and (v) times of 1 and $2 \mathrm{~h}$ do not differ significantly with respect to the lipid content extracted.

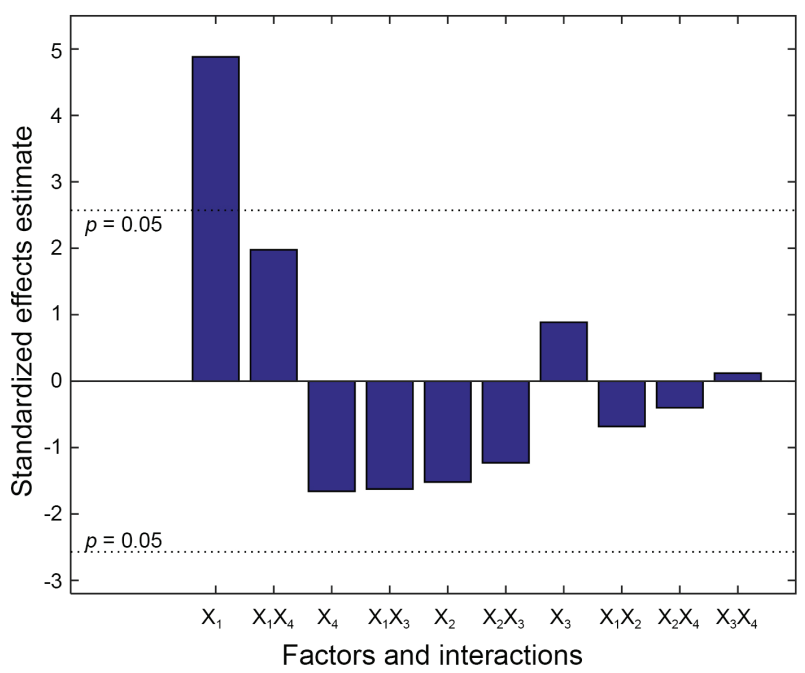

Figure 2. Pareto chart for the experiment design II with a horizontal dashed line corresponding to a significance level of $p=0.05$, which indicates the solvents mixture significance for the lipids extraction. The symbols are presented in Table $3 ; \mathrm{X}_{i} \mathrm{X}_{j}$ stands for the interaction between $i$ and $j$ factors.

In view of the results, the last investigation was carried out with respect to the extraction time, in order to verify whether the times of 4 and $6 \mathrm{~h}$ would increase the lipid extraction as only 1 and $2 \mathrm{~h}$ were considered before. Thus, based on the experimental design I and the effect of the primary parameters, the use of water bath, $\mathrm{CHCl}_{3}: \mathrm{MeOH}(2: 1)$, and ultrasonication at $60{ }^{\circ} \mathrm{C}$ were maintained as a pretreatment, solvent mixture, and method of extraction, respectively (the effects of the water bath and ultrasonication present negative signals according to the design proposed before, suggesting that the response increases at the lower levels). One-way ANOVA was used for the extraction time assessment $(2,4$ and $6 \mathrm{~h})$. The analyses were performed in triplicate under the conditions mentioned above and the results are shown in Table 5. The ANOVA (Table S1, Supplementary Information-SI section) showed that the extraction time was not significant on the total lipid yield $(F=3.04, p=0.1223)$, indicating that under the conditions studied the extraction is not expressively improved due to the time increasing, i.e., the time of $2 \mathrm{~h}$ is sufficient to promote the release of the lipids from the microalgae cells. At this point, it is worth mentioning that the absence of significant interactions verified in the 
experiment design I and the knowledge developed herein would encourage the accomplishment of a univariate study, even with the modification in the time levels. However, according to what has been exposed so far, the proposed multivariate approach is advantageous regarding the reduction in the number of experiments, time and energy.

Table 5. Total lipid yield obtained from Scenedesmus sp. for different extraction times. Conditions: water bath, ultrasonication extraction at $60{ }^{\circ} \mathrm{C}$ and $\mathrm{CHCl}_{3}: \mathrm{MeOH}(2: 1)$

\begin{tabular}{lccc}
\hline Extraction time / h & \multicolumn{3}{c}{ Total lipid yield / \% } \\
\hline 2 & 6.23 & 5.91 & 6.06 \\
4 & 5.17 & 5.98 & 7.65 \\
6 & 6.32 & 5.88 & 7.17 \\
\hline
\end{tabular}

\section{Back-extraction studies}

The lipid-extracted residual biomass was subjected to a back-extraction under the optimized conditions (Figure 3). For this, the results are presented as lipids per algal cellular dry weight (CDW in $\mathrm{mg} \mathrm{g}^{-1}$ of the biomass), due to its easiest visualization. The extraction performed with $\mathrm{CHCl}_{3}: \mathrm{MeOH}(2: 1)$ showed that the back-extraction reached $20 \%$ of the lipid quantity obtained with the first extraction procedure for $1 \mathrm{~h}$ and $15 \%$ for $2 \mathrm{~h}$. For the extraction performed with $\mathrm{CHCl}_{3}: \mathrm{EtOH}(2: 1), 34 \%$ of the first lipid yield obtaining was reached for $1 \mathrm{~h}$ and $15 \%$ for $2 \mathrm{~h}$.

According to Figure 3, such data corroborate, in a univariate manner, that the $\mathrm{CHCl}_{3}: \mathrm{MeOH}(2: 1)$ solvent mixture was the best choice since the amount of total lipid yield was much higher than that obtained with $\mathrm{CHCl}_{3}: \mathrm{EtOH}(2: 1)$; the original procedure perform the back-extraction procedure to guarantee an exhaustive extraction, ${ }^{38}$ right after the first extraction. We performed
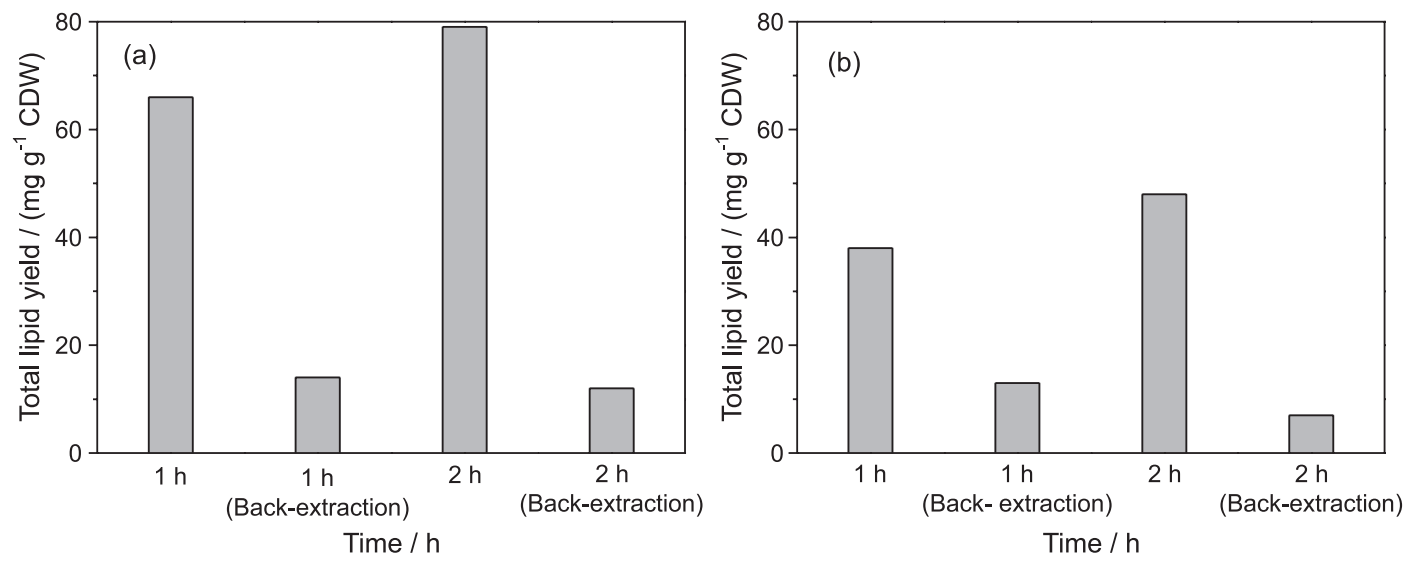

Figure 3. Ultrasonication-assisted lipid back-extraction under water bath at 1 and $2 \mathrm{~h}$ with (a) $\mathrm{CHCl}_{3}: \mathrm{MeOH}(2: 1)$ and (b) $\mathrm{CHCl}$ : $\mathrm{EtOH}(2: 1)$ solvent mixtures. here this procedure and collected the lipid obtained separately to study the efficiency of such a step.

\section{Fatty acid composition}

The main fatty acids identified in the lipid extracted were comprised of unsaturated esters for the $\mathrm{CHCl}_{3}: \mathrm{EtOH}(2: 1)$ and $\mathrm{CHCl}_{3}: \mathrm{MeOH}(2: 1)$ solvent mixtures. Considering the quality and quantity of FAME, there was no substantial difference between the extractions. As displayed in Table 6, the total quantity of unsaturated fatty acids was very similar for the mixtures. Thus, both solvents mixtures presented similar quality for FAME production, i.e., they are prompt to biodiesel production, even considering its lower oxidation stability. ${ }^{44,45}$ According to the literature, the unidentified compounds observed in Table 6 can be attributed to hydrocarbons of high molecular weight. ${ }^{46}$ Liu and $\mathrm{Liu}^{47}$ made a comprehensive study regarding the concentration of fatty acids in algae (59 species) and found out that $\mathrm{C} 16$ and $\mathrm{C} 18$, saturated or unsaturated, are the most abundant fatty acids, which is in accordance to our studies. However, Jay and Kawaroe ${ }^{48}$ studied the fatty acid composition of Chlorella vulgaris and observed more than $40 \%$ of saturated fatty acids with different carbon chains. Thus, comparisons are somehow difficult since the available nutrients for the microalgae cultivation directly affect the fatty acids profile observed. ${ }^{49,50}$

\section{Conclusions}

This study presented a multivariate approach for the optimization of total lipid extraction from Scenedesmus sp., using $2^{4}$ factorial designs and one-way ANOVA. We studied the solvent mixture, extraction method, extraction time and pretreatment and the optimum conditions observed were: ultrasonication for $2 \mathrm{~h}$ in a $\mathrm{CHCl}_{3}: \mathrm{MeOH}(2: 1)$ medium. 
Table 6. Profile of fatty acids of Scenedesmus sp. obtained from different extraction methods

\begin{tabular}{|c|c|c|c|}
\hline Name & Abbreviation & $\mathrm{CHCl}_{3}: \mathrm{MeOH} / \%$ & $\mathrm{CHCl}_{3}: \mathrm{EtOH} / \%$ \\
\hline Tetradecanoic acid & C14:0 & 0.84 & 1.16 \\
\hline 13-Methyltetradecanoic acid ${ }^{a}$ & - & 0.36 & 1.24 \\
\hline 12-Methyltetradecanoic acid ${ }^{a}$ & - & 0.15 & 0.62 \\
\hline Pentadecanoic acid & C15:0 & 0.56 & 0.91 \\
\hline Not identified & - & 3.77 & 0.59 \\
\hline Hexadec-4,7,10-trienoic acid & $\mathrm{C} 16: 3$ & 0.52 & 0.61 \\
\hline Not identified & - & 1.61 & 0.58 \\
\hline Hexadec-7,10-dienoic acid & $\mathrm{C} 16: 2$ & 1.30 & 1.03 \\
\hline Hexadecenoic acid isomers & $\mathrm{C} 16: 1$ & 1.70 & 1.49 \\
\hline Hexadec-9-enoic acid & C16:1 & 2.11 & 2.01 \\
\hline Hexadecenoic acid isomers & C16:1 & 5.68 & 6.26 \\
\hline Hexadecanoic acid & C16:1 & 32.59 & 38.67 \\
\hline Heptadecanoic acid & C16:1 & 0.63 & 1.35 \\
\hline Not identified & - & 0.60 & 1.07 \\
\hline Not identified & - & 0.75 & 1.02 \\
\hline Not identified & - & 1.11 & 1.65 \\
\hline Octadec-9,12,15-trienoic acid & $\mathrm{C} 18: 3$ & 0.70 & 1.22 \\
\hline Not identified & - & 1.11 & 1.28 \\
\hline Octadec-9,12-dienoic acid & $\mathrm{C} 18: 2$ & 4.94 & 5.10 \\
\hline trans-Octadec-9-enoic acid & C18:1 & 21.98 & 17.26 \\
\hline cis-Octadec-9-enoic acid & C18:1 & 8.04 & 7.43 \\
\hline Octadec-9,12-dienoic acid isomer & $\mathrm{C} 18: 2$ & 5.11 & 2.82 \\
\hline Octadecanoic acid & $\mathrm{C} 18: 2$ & 3.84 & 4.63 \\
\hline
\end{tabular}

Branched chain fatty acids do not present an abbreviation.

We attested that the only significant parameter was the solvent mixture and that this variable does not interact significantly with other variables. The present method can be easily applied in research laboratories due to a low-cost and low-power ultrasonication unit required. Although the study encourages a univariate study when compared to the literature, the multivariate optimization herein reported is highly advantageous due to the reduction of experiments numbers, which avoid waste of time, energy and reagents. In addition, although the fatty acid profile presents a high quantity of unsaturated compounds, biodiesel production can be performed, as previous studies have shown.

\section{Supplementary Information}

Supplementary data are available free of charge at http://jbcs.sbq.org.br as PDF file.

\section{Acknowledgments}

The authors are grateful to the Brazilian government agencies FAPEPI and CNPq for financial support.

\section{References}

1. Difiglio, C.; Energy Strateg. Rev. 2014, 5, 48.

2. Hu, W.; Bao, J.; Hu, B.; Adv. Pet. Explor. Dev. 2013, 40, 439.

3. Zou, C.; Zhao, Q.; Zhang, G.; Xiong, B.; Nat. Gas Ind. 2016, 3,1 .

4. Höök, M.; Tang, X.; Energy Policy 2013, 52, 797.

5. Howarth, R. W.; Santoro, R.; Ingraffea, A.; Clim. Change 2011, 106, 679 .

6. Gee, K. F.; Poon, H. Y.; Hashisho, Z.; Ulrich, A. C.; Sci. Total Environ. 2017, 598, 916.

7. Chen, R.; Qin, Z.; Han, J.; Wang, M.; Taheripour, F.; Tyner, W.; O'Connor, D.; Duffield, J.; Bioresour. Technol. 2018, 251, 249.

8. Ouanji, F.; Khachani, M.; Boualag, M.; Kacimi, M.; Ziyad, M.; Int. J. Hydrogen Energy 2016, 41, 21022.

9. Moazami, N.; Ashori, A.; Ranjbar, R.; Tangestani, M.; Eghtesadi, R.; Nejad, A. S.; Biomass Bioenergy 2012, 39, 449.

10. Balat, M.; Energy Convers. Manage. 2011, 52, 1479.

11. Ullah, K.; Ahmad, M.; Sofia; Sharma, V. K.; Lu, P.; Harvey, A.; Zafar, M.; Sultana, S.; Anyanwu, C. N.; Prog. Nat. Sci.: Mater. Int. 2014, 24, 329. 
12. Bhargavi, G.; Nageswara Rao, P.; Renganathan, S.; IOP Conf. Ser: Mater. Sci. Eng. 2018, 330, ID 012034.

13. Randrianarison, G.; Ashraf, M. A.; Geol., Ecol., Landscapes 2017, 1, 104.

14. Baicha, Z.; Salar-García, M. J.; Ortiz-Martínez, V. M.; Hernández-Fernández, F. J.; de los Ríos, A. P.; Labjar, N.; Lotfi, E.; Elmahi, M.; Fuel Process. Technol. 2016, 154, 104.

15. Ghasemi Naghdi, F.; González González, L. M.; Chan, W.; Schenk, P. M.; Microb. Biotechnol. 2016, 9, 718.

16. Halim, R.; Danquah, M. K.; Webley, P. A.; Biotechnol. Adv. 2012, 30, 709 .

17. Mäkelä, M.; Energy Convers. Manage. 2017, 151, 630.

18. Guldhe, A.; Singh, B.; Rawat, I.; Permaul, K.; Bux, F.; Fuel 2015, 147, 117.

19. Gupta, S. K.; Ansari, F. A.; Shriwastav, A.; Sahoo, N. K.; Rawat, I.; Bux, F.; J. Cleaner Prod. 2016, 115, 255.

20. Lorenzen, J.; Igl, N.; Tippelt, M.; Stege, A.; Qoura, F.; Sohling, U.; Bruck, T.; Bioprocess Biosyst. Eng. 2017, 40, 911.

21. Abomohra, A. E.; Jin, W.; El-sheekh, M.; Energy Convers. Manage. 2016, 108, 23.

22. Guldhe, A.; Singh, B.; Rawat, I.; Bux, F.; Chem. Eng. Res. Des. 2014, 92, 1503.

23. Gilbert-López, B.; Barranco, A.; Herrero, M.; Cifuentes, A.; Ibáñez, E.; Food Res. Int. 2017, 99, 1056.

24. Kim, S. M.; Jung, Y. J.; Kwon, O. N.; Cha, K. H.; Um, B. H.; Chung, D.; Pan, C. H.; Appl. Biochem. Biotechnol. 2012, 166, 1843.

25. Byreddy, A. R.; Gupta, A.; Barrow, C. J.; Puri, M.; Mar. Drugs 2015, 13, 5111.

26. Cravotto, G.; Boffa, L.; Mantegna, S.; Perego, P.; Avogadro, M.; Cintas, P.; Ultrason. Sonochem. 2008, 15, 898.

27. Zhao, X.; Zhang, X.; Fu, L.; Zhu, H.; Zhang, B.; Food Bioprod. Process. 2016, 99, 197.

28. Kapoore, R.; Butler, T.; Pandhal, J.; Vaidyanathan, S.; Biology 2018, 7, 18.

29. Lage, S.; Gentili, F. G.; Bioresour. Technol. 2018, 257, 121.

30. Rippka, R.; Deruelles, J.; Waterbury, J. B.; Herdman, M.; Stanier, R. Y.; Microbiology 1979, 111, 1.

31. Bligh, E. G.; Dyer, W. J.; Can. J. Biochem. Physiol. 1959, 37, 911.
32. Hartman, L.; Lago, R. C. A.; Lab. Pract. 1973, 22, 475.

33. Sharma, Y. C.; Singh, B.; Upadhyay, S. N.; Fuel 2008, 87, 2355.

34. Guldhe, A.; Rawat, I.; Ramluckan, K.; Bux, F.; Fuel 2014, 128, 46.

35. Cavonius, L. R.; Carlsson, N. G.; Undeland, I.; Anal. Bioanal. Chem. 2014, 406, 7313.

36. Chen, Z.; Wang, L.; Qiu, S.; Ge, S.; BioMed Res. Int. 2018, 3, ID 7191826.

37. Nelson, D. R.; Viamajala, S.; Catal. Today 2016, 269, 29.

38. Folch, J.; Lees, M.; Stanley, G. H. S.; J. Biol. Chem. 1957, 226 , 497.

39. Marchi, I.; Viette, V.; Badoud, F.; Fathi, M.; Saugy, M.; Rudaz, S.; J. Chromatogr. A 2010, 1217, 4071.

40. Cho, S. C.; Choi, W. Y.; Oh, S. H.; Lee, C. G.; Seo, Y. C.; Kim, J. S.; Song, C. H.; Kim, G. V.; Lee, S. Y.; Kang, D. H.; Lee, H. Y.; J. Biomed. Biotechnol. 2012, 2012, article ID 359432.

41. Albahari, P.; Jug, M.; Radić, K.; Jurmanović, S.; Brnčić, M.; Brnčić, S. R.; Vitali Čepo, D.; LWT - Food Sci. Technol. 2018, 92,22

42. Elik, A.; Talanta 2005, 66, 882.

43. Filgueiras, A. V.; Capelo, J. L.; Lavilla, I.; Bendicho, C.; Talanta 2000, 53, 433.

44. Knothe, G.; Dunn, R. O.; J. Am. Oil Chem. Soc. 2003, 80, 1021.

45. Chuck, C. J.; Jenkins, R. W.; Bannister, C. D.; Han, L.; Lowe, J. P.; Biomass Bioenergy 2012, 47, 188.

46. Sukahara, K. T.; Awayama, S. S.; J. Jpn. Pet. Inst. 2005, 48, 251.

47. Liu, H.; Liu, W.; Org. Geochem. 2017, 113, 17.

48. Jay, M. I.; Kawaroe, M.; IOP Conf. Ser. Earth Environ. Sci. 2018, 141 .

49. Darki, B. Z.; Seyfabadi, J.; Fayazi, S.; Braz. Arch. Biol. Technol. 2017, 60, ID e1760304, DOI 10.1590/1678-4324-2017160304.

50. Gupta, S. K.; Ansari, F. A.; Nasr, M.; Rawat, I.; Nayunigari, M. K.; Bux, F.; J. Cleaner Prod. 2017, 147, 419.

Submitted: October 2, 2018 Published online: December 3, 2018 